\title{
Looking Forward to a General Theory on Population Aging
}

\author{
Jean-Marie Robine ${ }^{1}$ and Jean-Pierre Michel $^{2}$ \\ ${ }^{1}$ INSERM, Health and Demography, University of Montpellier, France. \\ ${ }^{2}$ Geriatric Department, Geneva University Hospitals, Thônex-Geneva.
}

\begin{abstract}
The main theories on population aging based on recent data on human longevity, life expectancy, morbidity changes, disability trends, and mortality decrease are presented and discussed within their own geographic, cultural, socioeconomic, and medical contexts. The complex interactions between all these components do not facilitate trend forecasting of aging population (healthy aging versus disability pandemic). In the context of population aging, four elements were introduced with their implications: 1) an increase in the survival rates of sick persons, which would explain the expansion of morbidity, 2) a control of the progression of chronic diseases, which would explain a subtle equilibrium between the decrease in mortality and the increase in disability, 3) an improvement of the health status and health behaviors of new cohorts of elderly people, which would explain the compression of morbidity, and eventually 4) an emergence of very old and frail populations, which would explain a new expansion of morbidity. Obviously, all these elements coexist today, and future trend scenarios-expansion or compression of disability - depend on their respective weights leading to the need of elaborating "a general theory on population aging." This theory has to be based on a world harmonization of functional decline measurements and a periodic "International Aging Survey" to monitor global aging through a sample of carefully selected countries.
\end{abstract}

$\mathrm{R}$ ECENTLY, Freedman and colleagues published a systematic review of disability trends among older adults in the United States during the late 1980s and 1990s, showing consistent evidence of decline in physical functional limitations (difficulty lifting and carrying a bag of roughly 10 pounds, climbing stairs, and walking a quarter of mile) and conflicting evidence of decline in basic activities of daily living (ADL) disability (i.e., bathing, mobility, toileting, dressing, transfer from bed to chair, feeding) (1).

At the same time, Robine and colleagues collected evidence that ADL disability is clearly declining among the older people in Europe (2), especially in the United Kingdom, where the decrease in the inability to carry out ADLs was substantial over the period from 1976 to 1994 (3).

The lack of consensus on trends in personal care disability between the United States and Europe is disturbing all the more now that developing countries, such as Taiwan, today experience opposite trends in physical functional limitations (4). These apparently contradictory trends in functioning and disability, which were at the origin of numerous and interesting health theories (5-10), require a newer and wider conceptual framework, which will be first justified and then developed in the present article. The need of a general framework to organize the numerous findings related to aging has been recently underlined by others, but this was related more to mortality and longevity without great consideration for the population health status $(11,12)$.

\section{Models, Theories, and Data on the Evolution of Population Health Status}

\section{From Demographic Transition to Compression of Morbidity}

The present sustained increase in life expectancy at birth in low-mortality countries $(13,14)$ is no longer a surprise, as was the case a few years ago. From now on, the continuation of the increase in life expectancy at birth is due to the mortality decline at the highest ages (15), even if the exact causes of this fall in the oldest-old mortality rate are not yet clarified. Moreover, nobody knows what will be the future consequences in terms of age structure or in terms of health status of the population.

All conceptual health population models dated back to the 1970 s-1980s or even earlier, namely the demographic transition (5), the epidemiological transition (6), and the rectangularization of the survival curve and the compression of morbidity (9). In fact, these models shared the same framework: a) before the transition, mortality and fecundity were high, causes of deaths were linked to infectious diseases or accidental trauma, and the population was young, and b) after the transition, mortality and fecundity were lower but stable, and causes of deaths were degenerative or aging related. The population was old but the life expectancy was limited to 85 years with a small dispersion of individual life spans around this mean value. This limited life expectancy associated with the control of the risk factors (morbidity) would explain a rectangular 
survival curve for the whole population (called compression of morbidity) (9).

In this framework, the probabilities of survival above age 90 were low and little attention was given to changes in age structure or to changes in functional health status.

\section{Empirical Evidence and Alternative Scenarios} In Switzerland, for instance:

- At the beginning of the 1970 s, life expectancy at birth was 70.1 years for men and 76.2 years for women; $5.1 \%$ of men and $11.3 \%$ of women survived to age 90 in the mortality conditions of 1968-1973.

- 20 years later, in 1990 , life expectancy at birth was 74.0 years for men and 80.8 years for women; $10.1 \%$ of men and $25.1 \%$ of women survived to age 90 in the mortality conditions of 1988-1993.

- In 2001, life expectancy at birth was 77.2 years for men and 82.8 for women (16).

- In Japan, in 2001, life expectancy at birth reached 78.1 years for men and 84.9 years for women, $18.2 \%$ of men and $40.1 \%$ of women survived to age 90 in the mortality conditions of 2001 (17).

When it was realized in the 1980s that mortality was falling at old ages, the initial thought was linked to medical care progress allowing a longer survival. One then feared a pandemic of chronic diseases and disabilities $(8,18-21)$. For example, Fuchs wondered whether people escaped death from heart disease only to live in poor health (22). Manton opposed the fears of Gruenberg and Kramer to the optimism of Fries and proposed an alternative scenario in which the increased prevalence of chronic diseases was counterbalanced by a decrease in the severity of the same diseases (10). Following Manton, scholars built a conceptual framework with three main possibilities when mortality decreases among the old people:

1. An expansion of morbidity (chronic diseases and disability),

2. A dynamic equilibrium (between prevalence and severity),

3. A compression of morbidity (23-25).

\section{A New Measure: The Healthy Active Life Expectancy (HALE)}

As early as 1984, the World Health Organization (WHO) proposed a general model of health transition making possible the evaluation of the consequences of the increase in survival on health status. This model, which consisted of an extension of the notion of life expectancy to morbidity and disability, made possible the calculation of not only life expectancy, but also disease-free life expectancy and disability-free life expectancy (26). The constitution of chronological series on the prevalence of chronic diseases and disability in the population and the calculation of "healthy active life expectancies" provided the ability to monitor the consequences of the decrease in mortality among the oldest-old. These chronological series helped WHO experts to identify four different possible scenarios:
1. "A rectangularization of the survival curve," followed by a compression of morbidity and disability at the late ages of life, corresponding to Fries' theory (9), the disease-free and disability-free curves drawing nearer to the total survival curve;

2. "A pandemic of chronic diseases and disabilities," corresponding to Gruenberg's and Kramer's theories $(18,19)$, which would exclusively concern total survival;

3. "A lengthening of the biological life duration," corresponding to Strehler's theories (7), with a parallel shift of the three curves towards the right, illustrating a vast change in biological aging;

4. Finally, the case of relative independence in the evolution of the three curves, the interventions being liable, for example, to postpone the onset of diseases or reduce their disabling consequences.

This general model of health transitions was appealing, and, since its publication, many calculations have been carried out. Figure 1 shows an example of its application in France, where the increase in life expectancy during the period 1981-1991 was accompanied by a parallel increase in disability-free life expectancy while life expectancy without chronic diseases remained constant (see Figure 1). This apparent contradiction in the changes in disability and morbidity provided an example of the theory of dynamic equilibrium proposed by Manton in 1982. With the decline in mortality, the prevalence of reported chronic diseases increased but these diseases were on average less severe and induced less disability (27).

\section{REVES: The International Network on}

\section{Health Expectancy}

In this context and a few years later, an International Network on Health Expectancy and the Disability Process (http://www.prw.le.ac.uk/reves/) (the French acronym for which was REVES [Réseau d'Espérance de Vie en Santé]) was created to facilitate international collaboration in health expectancy calculations (2). Today, calculations are made for more than 50 countries and times series available in almost all low-mortality countries, in Europe (28), in North America (29), in Asia (30), or in Australia and New Zealand (31). The gathered calculations cover a 40 -year period, from 1958 to 1998 , and can be used to compare changes in life expectancy, disease free-life expectancy and disability freelife expectancy (all levels of disability combined), and "severe" disability free-life expectancy.

All together, these multiple, repeated, and harmonized calculations showed: a) a universal and regular increase in life expectancy at age 65 in the low-mortality countries since 1970; b) the same was not true for disability free-life expectancy, which appeared to stagnate. The gains in life expectancy might be years with disability (whatever the disability level); c) On the other hand, "severe" disabilityfree life expectancy evolved in parallel with life expectancy in all the countries in which data were available, namely, Australia , Canada, France, Japan, the United Kingdom, and the United States. This probably meant that if the years gained in life expectancy were years of life with disability, they were not with severe disability (32). 


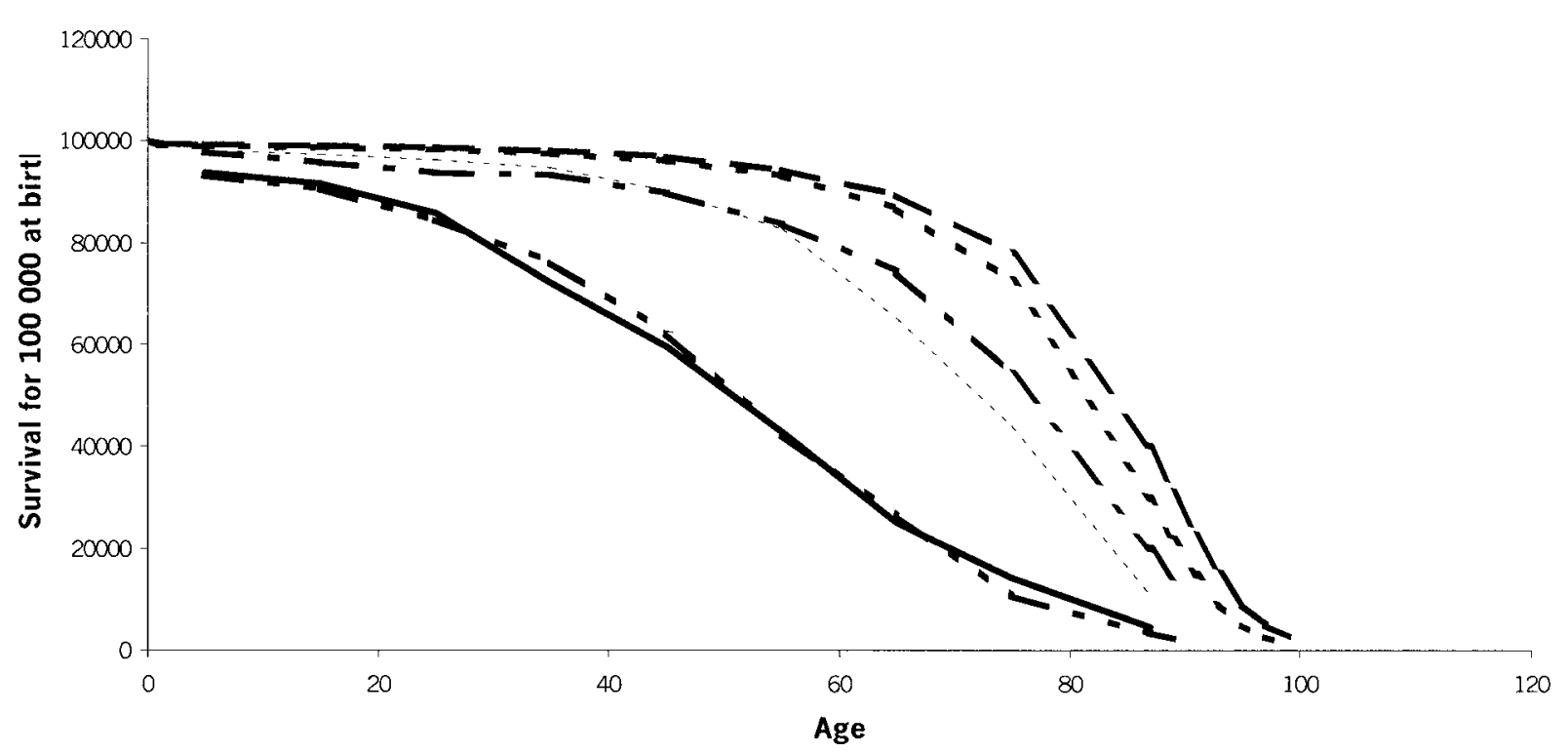

- - Total survival in 1981

- Survival without disease in 1981 -... Survival without disability in 1981

- Total survival in 1991

- - Survival without disease in 1991 - - Survival without disability in 1991

Figure 1. Survival without disease and survival without disability (World Health Organization model, 1984), France, 1981-1991, females.

The analysis of time series of disability-free life expectancy by severity level in comparison with trends in total life expectancy and life expectancy without disabling chronic or longstanding disease again supported the "theory of dynamic equilibrium," which partly explained the increase in life expectancy by a slowing down in the rate of progression of chronic diseases (10).

In the low-mortality countries, the decline in mortality among the oldest-old during the 1980s and 1990s was accompanied by an increase in the reported prevalence of chronic diseases and perhaps by an increase in the total prevalence of reported disability. But these diseases were on average less severe and led less often to severe levels of reported disability. The results indicate that, at worst, the increase in life expectancy is accompanied by a pandemic of light and moderate but not of severe disabilities (2).

\section{Contradictory Trends in Disability and Functioning}

In addition to these general results based on the notion of severity for disability, many studies relate to time series on the prevalence of various health conditions. Although some results are convergent, others are contradictory.

It clearly appeared that the reported prevalence of chronic diseases increased in low-mortality countries such as England (33), Finland (34), France, or the Netherlands. But these diseases were less often associated with reported disability (35-37). However, when one moved from reported diseases to reported functional limitations or reported disability, there was no longer convergence of the results.

Functional limitations.-In the United States, physical functional limitations among older people (difficulty lifting and carrying a bag of roughly 10 pounds, climbing stairs, and walking a quarter of a mile) decreased significantly in the 1980s and 1990s (37-39), suggesting an improvement in physical vigor. Similar results were found in the French Paquid survey with the items "climbing stairs and walking 500-1000 meters" for the period 1988-1998 and the 75-84year age group (40).

However, the opposite was observed for "problems climbing stairs" during the period 1981-1992 in New Zealand (3), for "seeing, hearing, and walking difficulties" during the period 1986-1998 in Quebec, Canada (41), or for "climbing and walking difficulties" during the period 1993-1999 in Taiwan (4). Moreover, disabling conditions and impairments (loss of sight, loss of hearing, incomplete use of arms or fingers, incomplete use of legs or feet, need for help, or supervision because of a mental illness or condition increased significantly during the period 1981-1998 in Australia (31). [For the most recent period, 1993-1998, "severe" disability-free life expectancy decreased in Australia (31)]. In Great Britain, the prevalence of several functional limitations reported in the 1996-1997 survey was much higher than in the earlier 1985 survey (42).

Finally, no change in physical functional limitations was found for the 55-84-year age group during the period 19921998 in the Netherlands (43), as well as no change in the level of blindness or hearing impairments among older Americans between 1984 and 1995 (44).

Mild disability and instrumental activities of daily living $(I A D L)$ difficulties.-Only France and the United States seemed to reveal a clear decline in physical functional limitations among older people and a significant decline in mild disability measured through activity restriction in daily 
life, such as "hampered in the daily life" in France and IADL restrictions in United States. In France, the decline in disability observed during the period 1981-1991 (45) was confirmed with the Paquid cohort for the 1988-1998 period. Independence significantly improved among the 75-84year-olds, thanks to a decline in mild disability for men and in ADL and IADL problems for women (40). In the United States, researchers found a consistent decline in IADL disability at age 65 years and older (46-53). In both countries, trends toward more educated elderly cohorts could partially explain the disability decline $(39,54)$, although other explanations can be entertained $(55,56)$. These trends could also be explained by an improvement in cognitive functioning $(57,58)$. Furthermore, in both countries, decline in institutional use was observed $(52,59)$. However, if a clear decline in institutional use before the age of 90 years was observed in France, the rate of institutionalization among those aged 90 years and older has significantly increased since 1975 due to the aging of this open-end age group (59); in the United States, the smaller proportion of persons living in a nursing home had greater disability in 1997 compared with 1985 (60). It is quite possible that Finland offered a third example of clear decline in disability since the 1980s (61). But in other countries such as Australia, Canada, Great Britain, and the Netherlands, mild disability seemed to be increasing.

Severe disability/ADL difficulties.-Severe disability, measured through ADL difficulties or bedridden and home confinement, appeared to decline in the United Kingdom, Finland, Switzerland, and France. Decrease in ADL disability among older persons was observed in the United Kingdom during the 1976-1994 period (3), in Finland during the 1986-1994 period (34), in Switzerland during the 1979-1994 period (62), and in France for women during the 1988-1998 period (40). Severe disability appeared to stagnate in the United States and the Netherlands. In the United States, for persons aged 70 and older, most of the decline in disability involved routine activity needs (IADLs) but not personal care needs (ADLs) $(49,53,63)$. In the Netherlands, there was no trend in severe disability (43). Severe disability has increased in Australia and perhaps in Japan. In Australia, severe disability substantially increased during the period 1993-1998, and in Japan, the inability to perform at least one ADL increased from 1992 to 1998 (64).

Perceived health.- It is now acknowledged that perceived health can follow a separate trend from disability $(65,66)$. It was especially feared or expected that perceived health would deteriorate even if functional status improved. However, several recent studies showed an improvement in perceived health of older people $(34,62)$. In Austria, for example, life expectancy in good perceived health at age 65 increased for women from 3.5 years in 1978 to 8.3 years in 1998 (67) (based on the health ratings "very good" and "good").

Synthesis and interpretative attempts.-In the United States, several authors tried to produce meaningful synthesis from these various data and trends $(20,48,63,65)$ and explored the possibility of a turning point in the $1980 \mathrm{~s}$ $(49,68)$. In 2002, Freedman and colleagues (58) published a systematic review of disability trends among the older adults during the late 1980s and 1990s, showing consistent evidence of decline in any disability, IADL disability and physical functional limitations, limited evidence of decline in cognitive functional limitation, and conflicting evidence of decline in basic ADL disability.

Several authors wondered whether opposite trends could correspond to different phases of the epidemiological transition. Robine, for example, wondered whether a general theory would make it possible to reconcile the various theories on the evolution of health status- "pandemic of disabilities," "dynamic equilibrium," and "morbidity compression"-which would only be the different stages of a single transition (24). Zimmer and colleagues tried to reconcile American and Taiwanese results on physical functional limitations by wondering again whether the expansion and compression of morbidity scenarios would be both correct but corresponding to different stages of the same transition (4). A recent study in the United States showed, by utilizing disability-free life expectancy calculations from 1970 to 1990 , that compression of morbidity began among those of higher educational status, whereas those of lower status were still experiencing expansion of morbidity (69) underlining again the need of a general theory on population aging and disability transition.

\section{Toward a General Theory on Population Aging}

Of course, several authors sought to improve the existing models of transition either by integrating new dimensions such as disability (70) or by adding a new stage into the fall of mortality - a fourth stage, such as the "Age of Delayed Degenerative Diseases" (71). But none of them basically reconsidered the demographic transition to fully account for population aging, which accompanied the various observed demoepidemiological changes. Such a general theory of population aging during the transition would deserve to cover at least 2 domains: 1) age structure modification over time including the emergence of new segments of the population such as the nonagenarians and centenarians, and 2) change in the functional health of the whole population.

\section{Age Structure and Transition}

The changes in age structure that accompany the various phases of demographic transition are often paradoxical and, for that reason, poorly understood. Thus, one knows or at least one should know that a decrease in mortality rejuvenates the population at the beginning of the transition. In the same way, population aging, in particular accelerated aging, so frequent in many developing countries does not inevitably increase the number of old people, at least at the beginning.

- In fact, during the demoepidemiological transition, the fall of mortality initially related to infant mortality inflated the number and the proportion of children with the consequence that there was a rejuvenation of the population.

- The fall of fertility, started in reaction to the surge of young people, immediately decreased the number and the 
proportion of children, whereas the number and the proportion of young adults swelled, leading to an increase of the mean age of the population.

- If the fall of mortality and fertility were simultaneous and quantitatively similar, the population would have known an accelerated rejuvenation followed by accelerated aging (at least 40 years are always needed for young adults to become old people). This time lag between the beginning of aging and the appearance of old people, especially visible in developing countries, is better identified by demographers and economists who used to speak of a demographic "gift" or "bonus," "golden age," or "window of opportunity" (72-74). Nowadays in the lowmortality countries (e.g., the most advanced in the transition), the fall of mortality immediately ages the population by directly increasing the number and the proportion of the oldest-old.

This general movement of transition, corresponding to a successive growth in the numbers of various age groups, initially children and teenagers, then young adults, and finally old people, led to the emergence of new segments of the population. Indeed, when the phase of growth reaches the last age group (the oldest-old), not only their numbers but also their life span increase. Thus, centenarians, exceptional until the end of the 19th century and rare until the end of World War II, become plethoric today (75). Their numbers have doubled approximately every 10 years since 1950 (76). People reaching the age of 105 years are increasingly frequent in the low-mortality countries such as Japan (77), and the maximum ages reported at death do not cease to increase (78). One hundred ten years of age is no longer an impassable limit (79).

\section{The Disability Transition}

Under such conditions, studying aging, health, and functioning changes of populations becomes central. The question does not concern the cause-of-death pattern changes, which were the basis of the epidemiological transition. The question now concerns the changes in the functional status pattern of the survivors that constitute the functional or "disability transition."

This question was first studied by Myers and colleagues $(70,80)$. They developed 9 theories describing the disability transition. The main idea was included in the first one: "Overall, crude rates of disability incidence are higher in the initial stages of an epidemiological transition and prevalence levels are lower. As the transition proceeds, a reversal in these levels occurs." With increased survival, the authors considered that the likelihood of comorbidities for an individual increases, thus leading to greater prevalence levels of disabilities. Theory 8 underlined that, in addition, reported prevalence might increase as individuals develop higher expectations of functional health. To that end, theory 9 underlined that the proportion of disability-free life expectancy was expected to decline during the transition.

In fact, several studies showed that the prevalence of disability was much lower in high-mortality countries, lending support to the first proposition. This is illustrated in a spectacular way by the comparison of the levels of disabilities of the Chinese and Danish centenarians; The level of reported disability was much lower in China than in Denmark (81). In Taiwan, at age 65 and older, difficulties in walking and climbing stairs increased between 1993 and 1999 contrary to what was observed in the United States (4), suggesting again that disability trends can be related to the different stages of the epidemiological transition. However, the published data do not allow comparison of the level in functional limitations in both countries. But the general idea is that at the beginning of the fourth stage of the epidemiological transition, the "Age of Delayed Degenerative Diseases" proposed by Olshansky and Ault (71), the fall of mortality concerns more the old or sick people having functional limitation and consequently increases the prevalence of disability among the population. This is the hypothesis behind the morbidity expansion scenario proposed in the 1980s by Gruenberg (8) and Kramer (19). Can we imagine that Taiwan is experiencing this scenario today whereas the United States is experiencing a compression of morbidity?

\section{Disability Versus Longevity}

Since the publication of the theory of compression of morbidity (9), vigorous discussions have been continuing on the possibility of obtaining a compression of morbidity at the end of the life span, due to a postponement of the functional decline, which would not involve in turn an increase in longevity. Recent studies suggested that improvement in health behaviors, such as better nutrition, smoking reduction, or increase in physical activities, would reduce morbidity more than increase longevity (82-86). Thus, if future increases in life expectancy are due to better behaviors, they could also be accompanied by larger increases in disability-free life expectancy leading to a compression of disability. Only provision of time series of both life expectancy and health expectancies will make it possible to answer the questions raised since the 1980s.

Outside the United States, long chronological studies are available for three countries: in Austria since 1978 with 4 points (67), in Great Britain since 1981 with 17 points $(33,87)$, and in Australia since 1981 also with 4 points (31) (two other studies should soon be available in Denmark, since 1987, and in the Netherlands, since 1989). In these three countries:

- Female life expectancy at age 65 clearly increased in the 1980s and 1990s (in Austria, from 15.2 years in 1978 to 17.5 years in 1998; in Great Britain, from 16.9 years in 1991 for women to 19.8 years in 1999; and in Australia, from 18.1 years in 1981 to 19.8 years in 1998 .

- Female disability-free life expectancy (various longstanding health problems) at age 65 varied greatly and in opposing ways: in Great Britain, it increased from 8.5 years in 1981 to 9.5 years in 1999; in Australia, it decreased from 10.0 years in 1981 to 9.0 years in 1998.

- Female life expectancy in good perceived health ("good" and "very good" together) increased both in Great Britain and Austria but much more strongly in Austria, from 3.5 years at age 65 for women in 1978 to 8.3 in 1998 $(31,33,67,87)$. 
Consequently, the proportion of years lived in good health decreased in Australia, remained constant in Great Britain, and increased in Austria. It is noteworthy that life expectancy at age 65 is initially higher in Australia, in between in Great Britain, and lower in Austria. Similar results are found for men. Overall, the comparison of these three chronological series shows that health expectancies are not evolving parallel to life expectancy, and it discloses different national patterns. Each study supports one possible scenario, expansion of morbidity in Australia between 1981 and 1998, dynamic equilibrium in Great Britain between 1981 and 1999, and compression of morbidity in Austria between 1978 and 1998. The comparison suggests a possible relationship between the initial value of life expectancy at age 65 and change in health expectancies. It suggests that expansion of disability goes with the highest life expectancy and compression of morbidity with the lowest.

A general theory of population aging, including the disability transition, should clearly take into account not only the decrease in mortality and the potential increase or decrease in disability, but also the initial levels of mortality and disability, pinpointing where the countries are in the transition stage. Only calculations of life and health expectancies provide all these elements. Their repetition at regular intervals allows correct assessments of changes over time. But today, they are very few and are using different morbidity or disability indicators, which prevents direct comparisons between countries and joint analysis.

At the oldest ages, from now on, frailty is added to functional decline and comorbidity. Frailty is a biologic syndrome of decreased physiological reserves and resistance to stressors causing vulnerability to adverse outcomes, independently of disability or comorbidity (88). The exhaustion of reserve, seen as redundancy, can explain late-life mortality deceleration $(12,89)$. At these limits, frail persons cease to be able to resist environmental hazards or resist extremely weakly (90), which could explain the mortality plateaus observed today at age 110 and older (79). In the same way, a general theory on population aging should integrate the emergence of the new segments of the population such as the nonagenarians and centenarians. Moreover, this general theory might explain the emergence of the frail population.

\section{A Draft Proposal}

In the first phase of the epidemiological transition, described by Omran in 1971 (6), modern economic developments resulted in a decrease in infant mortality due to increased food availability, decline in infectious diseases, and improvement of hygiene. All this progress initiated an important decrease in infant mortality (since one did not finally need large living improvements to obtain this infant mortality reduction). A greater number of newborns then carried out a "normal" life (91).

In the second phase, modern economic developments contributed to a lengthening of the "normal" life duration by reducing the mortality of older people. The fall of mortality among older people, which started shortly after WWII in the low-mortality countries (92), often raises very disturbing and interesting questions. Generally, it is explained by the considerable improvement in living conditions that elderly people discovered after WWII, including health and medical services availability. When older peoples' mortality started decreasing under the impact of economic, medical, and technical progress, it initially concerned a population in bad health in comparison with the current population of the same age. The fall of mortality then increased the prevalence of chronic diseases and disability by at first increasing the survival rates of sick persons. From that point on, sick persons had greater chances of survival. It is the scenario of morbidity expansion that could have occurred in the United States in the 1960s or 1970s (8) and which perhaps currently occurs in Taiwan (4). Gradually, medical progress could slow down the progression of chronic diseases involving a kind of equilibrium with mortality decline (10). It is the cardiovascular revolution (93) that could explain the turning points in disability trends that some researchers believed had been detected in the United States in the 1980s $(49,68)$. Progressively with the arrival of new cohorts, the health of the elderly population continues to improve. Many arguments go in this direction: a better adult life, a better educational level $(54)$, and better health practices $(55,56,94)$. All could lead to a compression of morbidity phase, which Austria, France, and the United States know today $(1,85)$. However, progress continues, particularly in the improved environment and services provided to the oldest-old. The fall of mortality leads from this point on to the emergence of extremely old populations like that of the supercentenarians and to the emergence of frail populations. These new phenomena could bring us back to the starting point, that is, to an expansion of morbidity. Would this be the scenario that Australia currently knows (31)?

\section{Temporary Conclusion}

Into this necessarily simplistic picture of population aging, we successively introduced four elements:

1. An increase in the survival rates of sick persons, which would explain the expansion of morbidity,

2. A control of the progression of chronic diseases, which would explain a subtle equilibrium between the fall of mortality and the increase in disability,

3. An improvement in health status and health behaviors of the new cohorts of old people, which would explain the compression of morbidity, and

4. An eventual emergence of the very old and frail populations, which would explain a new expansion of morbidity.

Obviously, all these elements coexist today and future scenarios, expansion or compression of disability, depend on their respective weights and lead to the need of elaborating a new general theory on population aging.

\section{Proposal to Facilitate Writing a Definite Conclusion}

To move ahead, two avenues can be proposed:

1. The first consists of setting up universal measurements of the functional decline, which one can combine with 
mortality data through time and all over the world. The need for such harmonization is so obvious that the G8 claimed it since its Denver Summit in 1997.

2. The second would consist of setting up a periodic International Aging Survey to monitor global aging through a sample of carefully selected countries. This second proposal can constitute an enthralling challenge for the gerontological community.

\section{ACKNOWLEDGMENT}

Partially funded by a grant from the French Institute of Longevity (GIS Institut de la Longévité) and by the IPSEN Foundation, Paris.

Address correspondence to Jean-Pierre Michel, Geriatric Department, Geneva University Hospitals, CH 1226, Thônex-Geneva, Switzerland. E-mail: jean-pierre.michel@hcuge.ch

\section{REFERENCES}

1. Freedman VA, Aykan H, Martin LG. Another look at aggregate changes in severe cognitive impairment: further investigation into the cumulative effects of three survey design issues. J Gerontol Soc Sci. 2002;57B:S126-S131.

2. Robine JM, Romieu I, Michel JP. Trends in health expectancies. In: Robine JM, Jagger C, Mathers $\mathrm{CD}$, et al. Determining health expectancies. Chichester: John Wiley; 2002:75-101.

3. Grundy E. The health and health care of older adults in England and Wales, 1841-1994. In: Charlton J, Murphy M, eds. The Health of Adult Britain 1841-1994. Vols. 1 and 2. London: The Stationery Office; 1997.

4. Zimmer Z, Martin LG, Chang MC. Changes in functional limitation and survival among older Taiwanese, 1993 and 1996. Pop Stud. 2002; $56: 265-276$

5. Notestein FW. Demographic studies of selected areas of rapid growth. In: Proceedings of the Round Table on Population Problems. 22nd Annual Conference of the Milbank Memorial Fund. New York: Milbank Memorial Fund; 1945.

6. Omran AR. The epidemiological transition: a theory of epidemiology of population change. Milbank Mem Fund Q. 1971;49:509-538.

7. Strehler BL. Implications of aging research for society. Fed Proc. 1975; 34:5-8.

8. Gruenberg EM. The failures of success. Milbank Mem Fund Q Health Soc. 1977;55:3-24.

9. Fries JF. Aging, natural death, and the compression of morbidity. N Engl J Med. 1980;303:130-135.

10. Manton KG. Changing concepts of morbidity and mortality in the elderly population. Milbank Mem Fund Q Health Soc. 1982;60:183244.

11. Carey JR. Longevity, the biology and demography of life span. Princeton: University Press; 2003.

12. Gavrilov LA, Gavrilova NS. The quest for a general theory of aging and longevity. Science of Aging Knowledge Environment. www.sageke.sciencemag.org/cgi/content/full/sageke;2003/28/re5

13. Oeppen J, Vaupel JW. Broken limits to life expectancy. Science. 2002; 296:1029-1031.

14. White KM. Longevity advances in high-income countries, 1955-96. Pop Dev Rev. 2002;28:59-76.

15. Vaupel JW, Carey JR, Christensen K, et al. Biodemographic trajectories of longevity. Science. 1998;280:855-860.

16. Heiniger M, Wanders AC. Portrait Démographique de la Suisse. Neuchâtel: Office Fédéral de la Statistique; 2002.

17. Ministry of Health and Welfare. Abridged Life Tables for Japan 2001. Statistics and Information Department, Minister's Secretariat, Ministry of Health and Welfare; 2001.

18. Gruenberg EM. Epidemiology of senile dementia. In: Epidemiology of Aging. Washington, DC: National Institutes of Health; 1980.

19. Kramer M. The rising pandemic of mental disorders and associated chronic diseases and disabilities. Acta Psychiatr Scand. 1980;62(Suppl. 285):282-297.
20. Verbrugge LM. Longer life but worsening health? Trends in health and mortality of middle-aged and older persons. Milbank Mem Fund $Q$ Health Soc. 1984;62:475-519.

21. Olshansky SJ, Rudberg MA, Carnes BA, et al. Trading off longer life for worsening health: the expansion of morbidity hypothesis. J Aging Health. 1991;3:194-216.

22. Fuchs VR. "Though much is taken": reflections on aging, health and medical care. Milbank Mem Fund Q Health Soc. 1984;62:143-166.

23. Crimmins EM. Are Americans healthier as well as longer-lived? $J$ Insurance Med. 1990;22:89-92.

24. Robine JM. Disability-free life expectancy. In: Robine JM, Blanchet M, Dowd JE. Health Expectancy. London: HMSO; 1992:1-22.

25. Nusselder WJ. Compression of morbidity. In: Robine JM, Jagger C, Mathers CD, et al. Determining health expectancies. Chichester: John Wiley; 2002:35-58.

26. World Health Organization. The Uses of Epidemiology in the Study of the Elderly. Report of a WHO Scientific Group on the Epidemiology of Aging. Geneva: WHO; 1984 (Technical Report Series 706).

27. Robine JM, Mormiche P, Cambois E. Evolution des courbes de survie totale, sans maladie chronique et sans incapacité en France de 1981 à 1991: application d'un modèle de l'OMS. Ann Demogr Hist (Paris). 1996:99-115.

28. Perenboom RJM, Van Oyen H, Mutafova M. Health expectancies in European countries. In: Robine JM, Jagger C, Mathers CD, et al. Determining health expectancies. Chichester: John Wiley; 2002: 359-376.

29. Lamb VL. Health expectancy research in North American countries. In: Robinr JM(??), Jagger C, Mathers CD, et al. Determining health expectancies. Chichester: John Wiley; 2002:377-390.

30. Saito Y, Qiao X, Jitapunkul S. Health expectancy in Asian countries. In: Robine JM, Jagger C, Mathers CD, et al. Determining health expectancies. Chichester: John Wiley; 2002:289-317.

31. Davis P, Mathers CD, Graham P. Health expectancy in Australia and New Zealand. In: Robine JM, Jagger C, Mathers CD, et al. Determining health expectancies. Chichester: John Wiley; 2002:391-408.

32. Robine JM, Romieu I, Cambois E. Health expectancy indicators. Bull WHO. 1999;77:181-185.

33. Kelly S, Baker A. Healthy life expectancy in Great Britain, 1980-96, and its use as an indicator in United Kingdom government strategies. Health Stat Q. 2000;7:32-37.

34. Aromaa A, Koskinen S, Huttunen J. Health in Finland. Helsinki: National Public Health Institute; 1999.

35. Robine JM, Mormiche P, Sermet C. Examination of the causes and mechanisms of the increase in disability-free life expectancy. J Aging Health. 1998;10:171-191.

36. Crimmins EM, Saito Y. Changes in the prevalence of diseases among older Americans: 1984-1994. Demogr Res. 2000;3:9.

37. Freedman VA, Martin LG. Contribution of chronic conditions to aggregate changes in old-age functioning. Am J Public Health. 2000; 90:1755-1760.

38. Freedman VA, Martin LG. Understanding trends in functional limitations among older Americans. Am J Public Health. 1998;88: $1457-1462$.

39. Freedman VA, Martin LG. The role of education in explaining and forecasting trends in functional limitations among older Americans. Demography. 1999;36:461-473.

40. Peres K, Barberger-Gateau B. Evolution de l'incapacité entre 75 et 84 ans. Gerontol Soc. 2001;98:49-64.

41. Saucher A, Lafontaine P. Prévalence et gravité de l'incapacité dans la population québécoise. In: Enquête Québecoise sur les Limitations d'Activité 1998. Ste-Foy: Les Publications du Québec; 2001.

42. Grundy E, Ahlburg D, Ali M, et al. Disability in Great Britain. London: HMSO, Department of Social Security; 1999 (Research Report 94).

43. Portrait F, Alessie R. Does physical disability of older individuals improve in the nineties. In: 14th Work Group Meeting REVES, Hammamet, Tunisia, April 2002. http://www.prw.le.ac.uk/reves/

44. Desai M, Pratt LA, Lentzner H, et al. Trends in vision and hearing among older Americans. Aging Trends. 2001;2:1-8.

45. Robine JM, Mormiche P. Estimation de la valeur de l'espérance de vie sans incapacité en France en 1991. Solidarité Santé. Etudes Statistiq. 1994;1:17-36.

46. Manton KG, Corder LS, Stallard E. Estimates of change in chronic disability and institutional incidence and prevalence rates in the U.S. 
elderly population from the 1982, 1984 and 1989 National Long Term Care Survey. J Gerontol B Psychol Sci Soc Sci. 1993;48:S153S166.

47. Manton KG, Corder LS, Stallard E. Chronic disability trends in elderly United States populations: 1982-1994. Proc Natl Acad Sci U S A. 1997;94:2593-2598.

48. Freedman VA, Soldo JS, eds. Trends in Disability at Older Ages. Washington, DC: National Academy Press; 1994.

49. Waidmann T, Bound J, Schoenbaum M. The illusion of failure: trends in self-reported health of the US elderly. Milbank $Q$. 1995;73: 253-287.

50. Crimmins EM, Saito Y, Reynolds SL. Further evidence on recent trends in prevalence and incidence of disability among older Americans from two sources: the LSOA and the NHIS. J Gerontol Soc Sci. 1997;52B: S59-S71.

51. Waidmann TA, Liu K. Disability trends among elderly persons and implications for the future. J Gerontol Soc Sci. 2000;55B:S298-S307.

52. Manton KG, Gu X. Changes in the prevalence of chronic disability in the United States black and non-black population above age 65 from 1982 to 1999. Proc Natl Acad Sci U S A. 2001;98:6354-6359.

53. Liao Y, McGee DL, Cao G, et al. Recent changes in the health status of the older US population: findings from the 1984 and 1994 supplement on aging. J Am Geriatr Soc. 2001;49:443-449.

54. Preston SH. Cohort succession and the future of the oldest old. In: Suzman RM, Willis DP, Manton KG. The Oldest Old. Oxford: Oxford University Press; 1992:50-57.

55. Cutler DM. The reduction in disability among the elderly. Proc Natl Acad Sci U S A. 2001;98:6546-6547.

56. Costa D. Changing chronic disease rates and long-term declines in functional limitation among older men. Demography. 2002;39: 119-137.

57. Freedman VA, Aykan H, Martin LG. Aggregate changes in severe cognitive impairment among older Americans: 1993 and 1998. J Gerontol Soc Sci. 2001;56B:S100-S101.

58. Freedman VA, Martin LG, Schoeni RF. Recent trends in disability and functioning among older adults in the United States. JAMA. 2002;288: 3137-3146.

59. Delbes C, Gaymu J. Aspects démographiques du grand âge. Gerontol Soc. 2001;98:11-22.

60. Sahyoun NR, Pratt LA, Lentzner H, et al. The changing profile of nursing home residents: 1985-1997. Aging Trends. 2001;4:1-8.

61. Martelin EJ. Toimintakykyisen elinajan viimeaikaiset muutokset ja kehitysnäkymät Suomessa. Kansallinen Foorumi: Aktiivinen ja elämään suuntautuva vanheneminen. 11 Februeay(??) 2002.

62. Lalive D'epinay C, Bickel JF, Maystre C, et al. Vieillesses au fil du temps 1979-1994. Lausanne: Réalités sociales; 2000.

63. Schoeni RF, Freedman VA, Wallace RB. Persistent, consistent, widespread, and robust? Another look at recent trends in old-age disability. J Gerontol Soc Sci. 2001;56B:S206-S208.

64. Saito Y. The changes in the level of disability in Japan: 1992-1998. In: XXIV IUSSP General Population Conference, Salvador, August 2001.

65. Crimmins EM. Mixed trends in population health among older adults. $J$ Gerontol Soc Sci. 1996;51B:S223-S225.

66. Spiers N, Jagger C, Clarke M. Physical function and perceived health: cohort differences and interrelationships in older people. J Gerontol Soc Sci. 1996;51B:S226-S233.

67. Doblhammer G, Kytir J. Compression or expansion of morbidity? Trends in healthy-life expectancy in the elderly Austrian population between 1978 and 1998. Soc Sci Med. 2001;52:385-391.

68. Crimmins EM, Ingegner DG. Trends in health among the American population. Paper prepared for the Pension Research Council Symposium, 1991.

69. Crimmins EM, Saito Y. Trends in healthy life expectancy in the United States 1970-1990: gender, racial, and educational differences. Soc Sci Med. 2001;52:1629-1641.

70. Myers G, Lamb V. Theoretical perspectives on healthy life expectancy. In: Robine JM, Mathers CD, Bone MR, et al., eds. Calculation of
Health Expectancies: Harmonization, Consensus Achieved and Future Perspectives: 6th REVES International Workshop, Montpellier, October 1992. Montrouge: John Libbey Eurotext; 1993:109-119.

71. Olshansky SJ, Ault AB. The fourth stage of the epidemiologic transition: the age of delayed degenerative diseases. Milbank Q. 1986; 64:355-391.

72. Williamson Jeffrey G. Demographic changes, economic growth, and inequality. In: Birdsall N, Kelley AC, Sinding SW, eds. Population Matters. Oxford: Oxford University Press; 2001.

73. Birdsall N, Sinding SW. How and why population matters: new findings, new issues. In: Birdsall N, Kelley AC, Sinding SW, eds. Population Matters. Oxford: Oxford University Press; 2001.

74. Vallin J. The end of the demographic transition: relief or concern? Pop Dev Rev. 2002;28:105-109.

75. Jeune B. In search of the first centenarians. In: Jeune B, Vaupel JW, eds. Exceptional Longevity: From Prehistory to the Present. Odense: Odense University Press; 1995:11-24 (Odense Monographs on Population Aging, 2).

76. Vaupel JW, Jeune B. The emergence and proliferation of centenarians. In: Jeune B, Vaupel JW, eds. Exceptional longevity: from prehistory to the present. Odense: Odense University Press; 1995: 109-116 (Odense Monographs on Population Aging, 2).

77. Robine JM, Saito Y, Jagger C. The emergence of extremely old people: the case of Japan. Exp Gerontol. 2003;38:735-739.

78. Wilmoth JR, Robine JM. The world trend in maximum life span. Pop Dev Rev. 2003;29(Suppl):239-257.

79. Robine JM, Vaupel JW. Emergence of super-centenarians in lowmortality countries. North Am Actuarial J. 2002;6:54-63.

80. Myers GC, Lamb VL, Agree EM. Patterns of disability change associated with the epidemiological transition. In: Robine JM, Jagger C, Mathers CD, et al. Determining health expectancies. Chichester: John Wiley; 2002:59-74.

81. Wang Z. Age validation, demographic characteristics and functional status among Chinese centenarians. University of Southern Denmark, Faculty of Health Sciences; 2000.

82. Vita AJ, Terry RB, Hubert HB, et al. Aging, health risks, and cumulative disability. $N$ Engl J Med. 1998;338:1035-1041.

83. Ferrucci L, Izmirlian G, Leveille SG, et al. Smoking, physical activity and active life expectancy. Am J Epidemiol. 1999;149:645-653.

84. Nusselder WJ, Looman CWN, Marang Van De Mheen PJ, et al. Smoking elimination produces compression of morbidity. J Epidemiol Community Health. 2000;54:566-574.

85. Hubert HB, Bloch DA, Oehlert JW, et al. Lifestyle habits and compression of morbidity. J Gerontol Med Sci. 2002;57A:M347M51(??).

86. Fries JF. Reducing disability in older age. JAMA. 2002;288:3164-3166.

87. Report: Healthy life expectancy in Great Britain, 1999. Health Stat $Q$ 2002;15:60-63.

88. Fried PL, Tangen CM, Walston J, et al. Frailty in older adults: evidence for a phenotype. J Gerontol Med Sci. 2001;56A:M146-M156.

89. Gavrilov LA, Gavrilova NS. The reliability theory of aging and longevity. $J$ Theor Biol. 2001;213:527-545.

90. Robine JM. Life course, environmental change, and life span. Pop Dev Rev. 2003;29(Suppl):229-238

91. Kannisto V. Mode and dispersion of the length of life. Population. 2001:13:159-171.

92. Robine JM. Redefining the stages of the epidemiological transition by a study of the dispersion of life spans: the case of France. Population. 2001;13:173-194.

93. Meslé F, Vallin J. Transition sanitaire: tendances et perspectives. Médecine/Sciences. 2000;16:1161-1171.

94. Allaire SH, LaValley MP, Evans SR, et al. Evidence for decline in disability and improved health among persons aged 55 to 70 years: the Framingham Heart Study. Am J Publ Health. 1999;89:1678-1683.

Received September 16, 2003

Accepted September 22, 2003 